\title{
Papaver Rhoeas L. Hydroalcoholic Extract Exacerbates Forced Swimming Test-Induced Depression in Mice
}

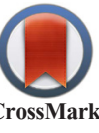

Naser Osanloo ${ }^{1}$, Akram Najafi-Abedi ${ }^{1}$, Fatemeh Jafari ${ }^{1}$, Farshid Javid ${ }^{1}$, Mohsen Pirpiran ${ }^{1}$, Mohammad-Reza Memar Jafari ${ }^{1}$, Seyed Ali Mousavi Khosravi', Mohammad Rahimzadeh Behzadi', Mina Ranjbaran ${ }^{1}$, Hedayat Sahraei ${ }^{1 *}$

Citation: Osanloo, N., Najafi-Abedi, A., Jafari, F., Javid, F., Pirpiran, M., Memar Jafari, M. R., et al. (2016). Papaver rhoeas L. hydroalcoholic extract exacerbates forced swimming test-Induced depression in mice. Basic and Clinical Neuroscience, 7(3), 195-202. http://dx.doi.org/10.15412/J.BCN.03070304

: http://dx.doi.org/10.15412/J.BCN.03070304

Article info:

Received: 05 April 2015

First Revision: 27 May 2015

Accepted: 21 October 2015
Key Words:

Papaver rhoeas,

Fluoxetine,

Corticosterone,

Locomotion, Stress

\begin{abstract}
A B S T RA C T
Introduction: Depression is one of the most frequent psychiatric disorders in the world with occurs with higher incidence in women. In the present study, the effect of water-alcoholic extract of Papaver rhoeas L. on forced swimming test (FST) in Swiss-Webster mice were examined.

Methods: We used Swiss-Webster mice (20-25 g) to execute FST on them. The plant extract (1, 10,30 , and $100 \mathrm{mg} / \mathrm{kg}$ ) was injected to the animals 30 minutes before each session. Fluoxetine $(20 \mathrm{mg} / \mathrm{kg}$ ) was used as standard antidepressant drug. In another group of animals, 30 minutes after extract administration, blood samples were taken from retro-orbital sinus for corticosterone assay. Yet in third group, the drugs were injected to the animals and 30 minutes later, their activities were tested in an open field apparatus.

Results: Our experiments showed that the extract efficiently reduced FST time both in male and female mice dose-dependently. This effect was comparable with fluoxetine. In addition, corticosterone assay indicated that plasma corticosterone in animals which received extract was higher than those amounts in fluoxetine and saline controls. Moreover, the animals did not show any motor activity deficit in all doses of the extract and fluoxetine compared to saline control.

Conclusion: The extract of Papaver rhoeas can reduce immobility time which is comparable to the effect of fluoxetine. Also the effect of the extract is contrary to its effects on plasma corticosterone level and or animals' activity.
\end{abstract}

\section{Introduction}

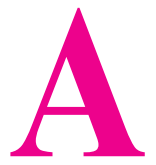

ccording to the World Health Organization report, depression is the second leading debilitating factor in humans after cardiovascular diseases and leads to enormous socioeconomic losses (Beck \& Alford, 2009). This disease has a complex pathophysiology, and more importantly, a large overlap exists between this disease and stress (Drevets, Price, \& Furey, 2008; MacDonald, 1997; Mann, 2005). The main factors underlying the incidence and persistence of this disease include brain monoamine receptors dysfunction, reduced secretion and synthesis of monoamines such as norepinephrine, and possibly brain cells' secondary

* Corresponding Author:

Hedayat Sahraei, $P h D$

Address: Neuroscience Research Center, Baqiyatallah (a.s.) University of Medical Sciences, Tehran, Iran.

Tel: +98 (21) 26127286

E-mail: hsahraei1343@gmail.com 
monoamine receptors dysfunction (Berton \& Nestler, 2006; Blier \& de Montigny, 1994; Drevets, Price, \& Furey, 2008; MacDonald, 1997; Mann, 2005). Recent studies have shown that increased cortisol and its damaging effect on neurogenesis through reduced nerve growth factor, disruption of endogenous opioid activity, and changes of GABA (gammaaminobutyric acid) or glutamate activities, reduced cytokine activity in the brain, steroid activities in the brain, and abnormal circadian period can affect the incidence of depression (Caspi et al., 2003; Dantzer, O'Connor, Freund, Johnson, \& Kelley, 2008; Drugan et al., 2013; Pariante \& Lightman, 2008; Raison, Capuron, \& Miller 2006; Southwick, Vythilingham, \& Charney, 2005). Although many studies have been conducted on the synthesis of new antidepressants, the latest findings indicate that less than half of the depressed patients have recovered after using these drugs (Nestler et al., 2002). As a result, research on antidepressant chemicals of herbal origin is expanding across the world now (Drew \& Myers, 1997). Research on medicinal plants, especially for the treatment of psychiatric and nervous disorders, is very important. A study on depressed people showed that more than $57 \%$ of those with major depression experienced better results with using herbal medications than conventional treatments (Drew \& Myers, 1997; Sarris, 2007).

In previous studies conducted by the same research group, Papaver rhoeas L. hydroalcoholic extract was shown to reduce the metabolic effects of stress in mice (Mirzaei, Lotfi Kashani, Behzadi, \& Sahraie, 2013). Previous studies also examined the effect of the extract of this plant on withdrawal syndrome (Pourmoteabbed et al., 2004), conditioned place preference (Sahraei et al., 2006b), and behavioral sensitization (Sahraei et al., 2006a) in mice. Papaver rhoeas (PR) is a $25-90 \mathrm{~cm}$ tall herbaceous plant with red flowers that grows in various parts of the country. This plant contains various alkaloids, such as rhoeadine, rhoeadic acid, papaveric acid, mechoic acid, mucilage, and sugar (Zargari, 1994; El \& Karakaya, 2004; Gürbüz, Üstün, Yesilada, Sezik, \& Kutsal, 2003; Hillenbrand, Zapp, \& Becker, 2004; Pfeifer, 1965; Schaffer, Schmitt-Schillig, \& Muller, 2005; Winkler \& Awe, 1961; El-Masry, El-Ghazooly, Omar, Khafagy, \& Phillipson, 1981; Kalav \& Sariyar, 1989; Soulimani, Younos, JarmouniIdrissi, Bousta, Khalouki, \& Laila, 2001). Historically, this plant was brewed and used to relieve insomnia and reduce inflammation (Zargari, 1994). It also has sedative and mucus relief effects, and is referred to as "harmless opium" due to small amount of morphine in its extract (Zargari, 1994).

Given the anti-opioid (Zargari, 1994), antidopaminergic, and anticholinergic (Saeed-Abadi et al., 2012) effects of PR extract and the role of these agents in the incidence of depression, the present study set out to examine the effect of the extract of this plant on forced swimming test (FST) stress- induced depression in mice. Since the incidence of depression is more frequent in females than in males, the study also made comparisons between genders. Finally, as hypothalamic-pituitary adrenal activity is recognized the main cause of depression (Pariante \& Lightman, 2008), this study also investigated the effect of this extract on the activation of the aforementioned system's functions by measuring plasma corticosterone concentrations (Krishnan \& Nestler, 2011; Lucki, 1997).

\section{Methods}

\subsection{Animals}

The present study used tiny male and female NMRI mice weighing 25 to $30 \mathrm{~g}$ (6 in each group). The mice were kept at the animal room of the Neuroscience Research Center of Baqiyatallah University at $23 \pm 2^{\circ} \mathrm{C}$ under alternating $12: 12$ hour light-dark cycle. The mice were given standard mouse food and water except during the experiments. Each animal went under experiments only once.

\subsection{Forced swimming test}

The experiment was conducted on two consecutive days. For this experiment, a glass container $25 \mathrm{~cm}$ in height and $12 \mathrm{~cm}$ in diameter was filled up to $8 \mathrm{~cm}$ with water at $25^{\circ} \mathrm{C}$, and the mice were gently released into the water from $20 \mathrm{~cm}$ above. The discontinuation of the movement of the mice' limbs is considered immobility (Porsolt, Deniel, \& Jalfre, 1979). The experiment was conducted for all groups between 9 AM and 4 PM under similar conditions. The forced swimming test lasted a total of 6 minutes. The first two minutes were taken as the adjustment time to the conditions for the mice and their immobility during this time was not recorded. Immobility was recorded for the next 4 minutes (Porsolt, LePichon, \& Jalfre, 1977).

On the first day of the experiment, the mice were released into the water container for 15 minutes and then removed, dried, and returned to their cages. On the second day, the mice were released into the water container and their first two minutes were not recorded. All movements of the mice were recorded for the next 4 minutes and their immobility time was calculated by deducting their mobility time from the total time (4 minutes).

\subsection{Drugs}

We used Papaver rhoeas (PR) L. hydroalcoholic extract and fluoxetine hydrochloride (Sigma, US). All medications were dissolved in distilled water and administered intraperitoneally at a dose of $10 \mathrm{mg} / \mathrm{kg}$ (30 minutes before the experiment). The control group was administered an identical volume of saline intraperitoneally. 


\subsection{Blood sample collection}

The mice were gently held in hand and placed on a table, and then $500 \mu \mathrm{L}$ of blood was taken from their retro-orbital sinus using a micropipette dipped in sodium citrate. The blood was then transferred into a $1.5 \mathrm{~mL}$ Eppendorf tube containing $200 \mu \mathrm{L}$ of sodium citrate solution. Next, they were centrifuged at $3000 \mathrm{rpm}$ for 5 minutes in a refrigerated centrifuge at $4^{\circ} \mathrm{C}$, and the supernatant was transferred to a freezer at $-20^{\circ} \mathrm{C}$ to proceed with the rest of the experiment.

\subsection{Plasma corticosterone measurement}

After collecting blood samples from the mice retro-orbital sinus and their subsequent centrifugation, $20 \mu \mathrm{L}$ of each plasma sample was transferred to the corticosterone ELISA plate, and after being mixed with the substances and their subsequent incubation at $37^{\circ} \mathrm{C}$, the optical absorbance of the samples was read at a wavelength of $450 \mathrm{~nm}$ by the ELISA reader. Plasma corticosterone concentration was calculated by placing the numbers read on the curve yielded by the optical absorbance of the controls against the standard corticosterone curve.

\subsection{Mice mobility assessment}

An open field apparatus was used to assess the mice motor activity. It is composed of a metallic cylinder $25 \mathrm{~cm}$ in diameter and $30 \mathrm{~cm}$ in height placed on a wooden surface of the same diameter (Sahraei et al., 2006a). The wooden surface was divided with intersecting lines $5 \mathrm{~cm}$ apart. This apparatus functions in a way that whenever the mouse's head and two forelimbs cross over one of these lines, the mouse receives 1 score. The number of lines crossed in a given period of time is indicative of the mouse's rate of motor activity. At first, each animal was left to roam free around the apparatus for 10 minutes to get used to the environment, and then its motor activity was recorded for a period of 10 minutes.

\subsection{Plant extraction}

Papaver rhoeas (PR) picked up from Kermanshah Province (western Iran) was shade-dried and transferred to the Pharmacognosy laboratory of Shahid Beheshti University of Medical Sciences, School of Pharmacy, where it was identified by Mohammad Kamalinejad and given the code P-147. Then, the plant was grounded into a powder. Using a digital scale, $100 \mathrm{~g}$ of the powder was taken and poured into a beaker and mixed with $500 \mathrm{~mL}$ absolute ethanol $(100 \%)$ and $500 \mathrm{~mL}$ distilled water, and was then covered with a foil and left in the laboratory room (at $25-27^{\circ} \mathrm{C}$ ) for 24 hours. The solution was gently stirred over this period. Afterwards, the supernatant was separated and filtered several times using filter paper and cone filter and then poured into a fitting container and kept in the laboratory room for 24 hours. The condensed liquid was then poured into a glass container (to ease the extract separation) and left for another 24 hours to allow the evaporation of alcohol and water and obtain the dry extract. The obtained extract was then dissolved in saline and administered to the mice at $10 \mathrm{~mL} / \mathrm{kg}$.

\subsection{Experimental design}

\subsubsection{Effects of Papaver rhoeas extract on immobility time}

In this experiment, we examined the effects of different doses of PR extract on FST- induced depression, i.e., immobility. Six groups of mice (for each sex) were treated with PR extract $(1,10,30$, and $100 \mathrm{mg} / \mathrm{kg} \mathrm{IP})$, fluoxetine $(10 \mathrm{mg} / \mathrm{kg}$; IP), or saline ( $10 \mathrm{ml} /$ mouse) 30 minutes before the test.

\subsubsection{Effects of Papaver rhoeas extract on plasma cor-} ticosterone level

In this experiment, we examined the effects of different doses of PR extract on plasma corticosterone level. Six groups of mice (for each sex) were treated with PR extract $(1,10,30$, and $100 \mathrm{mg} / \mathrm{kg} \mathrm{IP})$, fluoxetine $(10 \mathrm{mg} / \mathrm{kg}$; IP), or saline $(10 \mathrm{~mL} /$ mouse) 30 minutes later, blood samples were taken from the mice retro-orbital sinus.

\subsubsection{Effects of Papaver Rhoeas extract on locomotor activity}

In this experiment, the effects of different doses of PR extract on locomotor activity were examined. Six groups of mice (for each sex) were treated with PR extract $(1,10,30$, and $100 \mathrm{mg} / \mathrm{kg} \mathrm{IP})$, fluoxetine $(10 \mathrm{mg} / \mathrm{kg}$; IP), or saline (10 $\mathrm{mL} /$ mouse) 30 minutes before the test.

\subsection{Statistical analysis}

Results were showed as the mean \pm standard deviation of the mice's immobility duration. Data were analyzed using the 1-way analysis of variance and Tukey post hoc test. The level of significance was set at $\mathrm{P}<0.05$ for all the differences. SPSS-9.01 software was used for the statistical analyses.

\section{Results}

3.1. Examining the effect of the intraperitoneal administration of Papaver rhoeas L. hydroalcoholic extract on FST stress-induced immobility

The 6 groups of male mice received an intraperitoneal administration of either saline $(10 \mathrm{~mL} / \mathrm{kg})$, fluoxetine $(20 \mathrm{mg} /$ $\mathrm{kg}$ ) or the various doses of the PR extract $(1,10,30$ and 100 


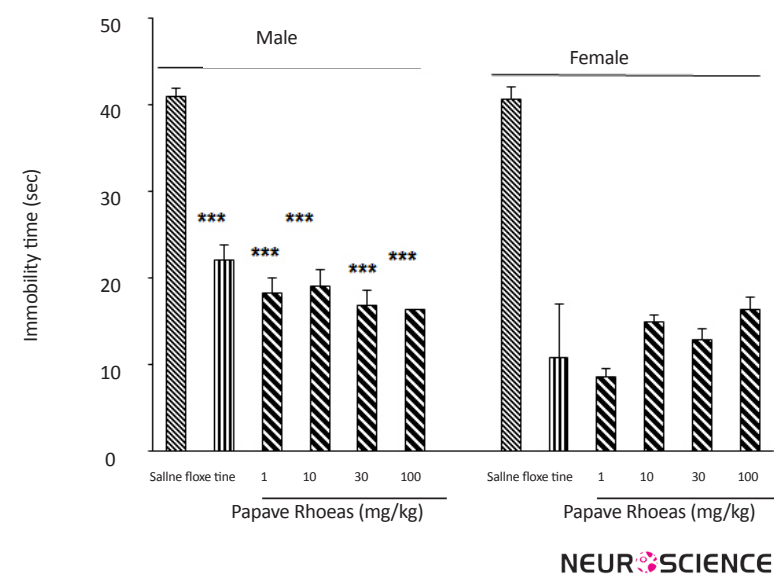

Figure 1. Effects of different doses of Papaver rhoeas extract on immobility time reduction in male and female mice. The extract reduces the immobility time in both genders, which is comparable to fluoxetine effect. Moreover, the PR extract and fluoxetine were more effective in female than the male animals. *** $\mathrm{P}<0.001$ compared to saline group.

$\mathrm{mg} / \mathrm{kg}$ ) 30 minutes before the cold water swimming-induced stress (Figure 1). Results of the study showed that the administration of the extract at different doses reduced the duration of immobility $(\mathrm{F}(5,30)=4.28, \mathrm{P}<0.001)$.

The 6 groups of female mice also received an intraperitoneal administration of either saline $(10 \mathrm{ml} / \mathrm{kg})$, fluoxetine $(20$ $\mathrm{mg} / \mathrm{kg}$ ), or various doses of the PR extract $(1,10,30$ and 100 $\mathrm{mg} / \mathrm{kg}$ ) 30 minutes before the cold water swimming-induced stress (Figure 1). Results of the study showed the administration of the PR extract at different doses reduced the duration of immobility $(\mathrm{F}(5,30)=5.8, \mathrm{P}<0.001)$. Comparison of the

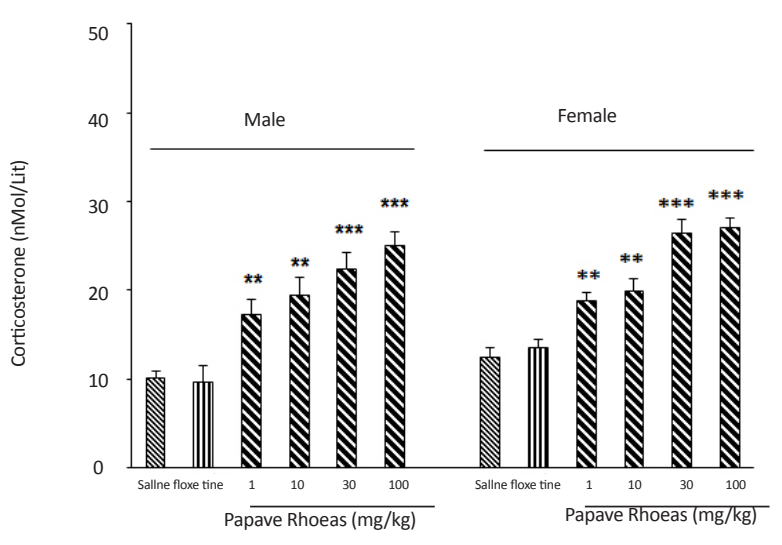

NEUR:SCIENCE

Figure 3. Effects of different doses of P. rhoeas extract and fluoxetine on plasma corticosterone concentration elevation in male and female mice. The extract can increase corticosterone level in both animals in dose-independent manner.

${ }^{* * *} \mathrm{P}<0.001$ and ${ }^{* *} \mathrm{P}<0.01$ compared to fluoxetine and saline group.

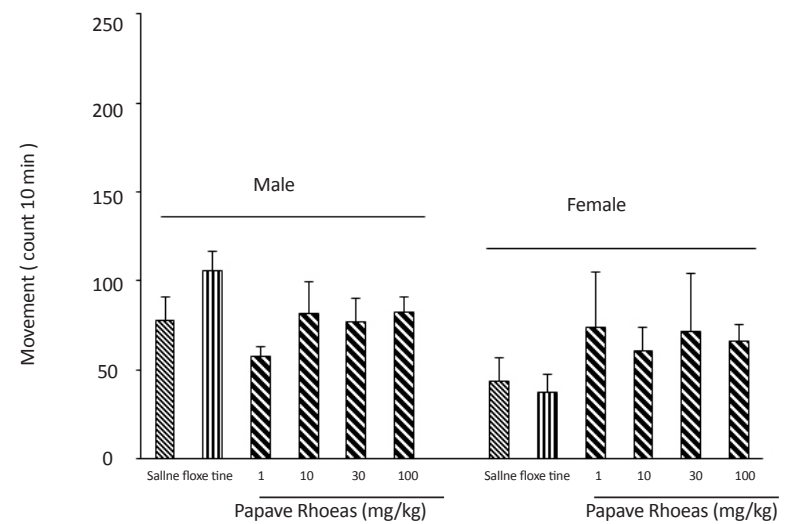

NEUR:SCIENCE

Figure 2. Locomotor activity changes after different doses of Papaver rhoeas and fluoxetine administration in male and female mice. It is clear that the extract did not change the animals' activity compared to fluoxetine and saline group.

groups of male and female mice showed that both were sensitive to the induced stress method; however, female mice responded more severely to the extract and fluoxetine.

3.2. Examining the effect of the intraperitoneal administration of Papaver rhoeas L. hydroalcoholic extract on motor activity

The 6 groups of male mice received an intraperitoneal administration of either saline $(10 \mathrm{~mL} / \mathrm{kg})$, fluoxetine $(20 \mathrm{mg}$ ) $\mathrm{kg}$ ) or the various doses of the PR extract (1, 10, 30 and 100 $\mathrm{mg} / \mathrm{kg}$ ) 30 minutes before the mobility assessment (Figure 2). Results of the study showed the administration of the extract at different doses had no effect on the mice motor activity $(\mathrm{F}(5,30)=1.012, \mathrm{P}<0.05)$.

The 6 groups of female mice also received an intraperitoneal administration of either saline $(10 \mathrm{~mL} / \mathrm{kg})$, fluoxetine $(20 \mathrm{mg} / \mathrm{kg})$, or various doses of the PR extract $(1,10,30$ and $100 \mathrm{mg} / \mathrm{kg}$ ) 30 minutes before the mobility assessment (Figure 2). Results of the study showed that the administration of the extract at different doses used and the fluoxetine slightly increased the mice mobility $(\mathrm{F}(5,30)=1.65, \mathrm{P}<0.05)$.

3.3. Examining the effect of the intraperitoneal administration of Papaver rhoeas L. hydroalcoholic extract on plasma corticosterone concentration

The 6 groups of male mice received an intraperitoneal administration of either saline $(10 \mathrm{~mL} / \mathrm{kg})$, fluoxetine $(20 \mathrm{mg} /$ $\mathrm{kg}$ ), or various doses of the PR extract $(1,10,30$ and 100 $\mathrm{mg} / \mathrm{kg}$ ), and 30 minutes later, blood samples were taken from their retro-orbital sinus, to measure their plasma corticosterone concentration (Figure 3). Results of the study showed the administration of the extract at different doses 
increased plasma corticosterone concentration in the mice $(\mathrm{F}(5,30)=3.56, \mathrm{P}<0.001)$.

The 6 groups of female mice also received an intraperitoneal administration of either saline $(10 \mathrm{ml} / \mathrm{kg})$, fluoxetine $(20 \mathrm{mg} / \mathrm{kg})$, or various doses of the extract $(1,10$, 30 and $100 \mathrm{mg} / \mathrm{kg}$ ) and 30 minutes later, blood samples were taken from their retro-orbital sinus, to measure their plasma corticosterone concentration (Figure 3). Results of the study showed that the administration of the extract at the doses increased plasma corticosterone concentration in the mice $(\mathrm{F}(5,30)=4.21, \mathrm{P}<0.001)$.

\section{Discussion}

The present study investigated the effect of Papaver rhoeas L. hydroalcoholic extract on reducing depression caused by FST-induced stress in male and female mice. Results of this study showed that the administration of this extract reduced depression in mice (longer mobility of mice in water), which was comparable to the effect of fluoxetine as a standard antidepressant. Administration of the extract also increased plasma corticosterone concentration, which is the main glucocorticoid hormone secreted by the mice adrenal gland during stress. The PR extract did not affect the mice mobility. Therefore, the antidepressant effect of the extract may not be due to the inhibition of hypothalamic-pituitary-adrenal stress system or stimulation of movements in the animals.

In pathophysiological terms, the reduced concentration of neurotransmitters such as serotonin, norepinephrine, and dopamine cause depression, and all approved antidepressants increase the activity of at least one of these chemical transmitters (Berton \& Nestler, 2006; Nestler et al., 2002; Southwick, Vythilingham, \& Charney, 2005). Results of the present study, in which the administration of Papaver rhoeas L. hydroalcoholic extract reduced depression in mice, could indicate that the extract of this plant increases at least one of the neurotransmitters involved in depression such as serotonin, dopamine, or norepinephrine (Beck \& Alford, 2009). Researchers have shown that depression is directly associated with stress and increased glucocorticoids secretion into the blood (Drugan et al., 2013). However, in the present study, administration of Papaver rhoeas L. extract increased the secretion of this hormone, which shows that the depression-inhibiting effect of the extract has not been due to the inhibition of corticosterone secretion (the main glucocorticoid secreted in mice).

The present study also showed that the effect of the extract was not due to its involvement in the mice motor activity. Numerous studies have been conducted on the various effects of PR extract, and the present study also showed that the extract of this plant has major depression-inhibiting effects. Previ- ous studies have shown that PR extract has immense effects on numerous animal models, including physical and mental morphine-dependence (Pourmotabbed et al., 2004; Sahraei et al., 2006b), morphine responsiveness and behavioral tolerance (Sahraei et al., 2007), and tolerance to the analgesic effects of morphine (Shams et al., 2008). Recent studies, however, have shown the effect of this plant in inhibiting the metabolic effects of stress in male mice (Mirzaie et al., 2013). This extract also boosts memory and inhibits memory loss due to stress in mice (Mirzaie et al., 2013).

All these studies indicate the beneficial effects of the PR extract. The effective compounds in Papaver rhoeas L. hydroalcoholic extract to reduce depression have not identified yet. However, previous researchers have shown that the extract contain anthocyanin, which might reduce depression through interactions with dopamine receptors and their subsequent inhibition (Sahraei et al., 2007). It should be noted that presynaptic dopamine $\mathrm{D}_{2}$ receptors are positioned on dopamine terminals, and their inhibition increases the release of dopamine, which is an effective neurotransmitter in reducing depression (MacDonald, 1997; Mann, 2005). To better understand the effect of this extract, the interaction between the extract and dopamine system is suggested to be examined.

The majority of studies conducted on Papaver rhoeas indicate the presence of papaveric acid, papaverine, and muconic acid in its extract, which are among the most effective compounds on brain neurotransmitters. Previous studies have also shown the anti-glutamate effects of the PR extract (Saeed-Abadi et al., 2012). Since the inhibition of glutamate is currently considered one of the best ways to reduce depression, it appears that the effect of this extract is at least partially caused by this mechanism. Furthermore, this extract also has antiopioid and anticholinergic effects that might have been influential as well. Although the antianxiety effect of the extract was not examined in the present study, it might be helpful to study this particular effect to better understand the effects of this plant.

In the present study, a slight difference was observed between the male and female mice in their response to this extract, which might indicate gender differences in stress-induced depression and treatment. Previous studies have shown the greater sensitivity of the female brain to stress compared to the male brain, which might be the reason for this difference. The difference in responsiveness was also observed with fluoxetine. No comprehensive research has yet been conducted on this topic, though a review seems essential.

In this study, the PR extract did not appear to have any inducing or inhibiting effect on the mice's motor activity in either gender. Previous studies did not report any motor- 
activity effect for the extract either, and in our previous study, the extract showed no effect on the animals' mobility in and of itself (Sahraei et al., 2006a; Sahraei et al., 2007). The extract therefore appears to be unable to affect animals' motor activity function, an effect which is easily discernible with morphine (Sahraei et al., 2006a). The important point is the fluoxetine effect in increasing motor activity in female mice compared to male mice. This effect of fluoxetine has not yet been reported, but it might be due to the ability of fluoxetine in increasing extracellular dopamine concentration in the brain (Ettehadi et al., 2013), even though the center of this increase does not properly match the motor control center.

The present study showed that the extract is capable of stimulating plasma corticosterone concentration increase in male and female mice, which was not the case with fluoxetine. Our previous study also confirmed the effect of the extract on increasing the plasma corticosterone concentration in mice (Saeed-Abadi et al., 2012; Mirzaie et al., 2013). Although several studies directly refer to the increasing effect of glucocorticoid hormones due to stress and their effect on the incidence of mental fatigue, reduced brain monoamines, and depression (Pariante \& Lightman, 2008), the present study showed that this extract does not exacerbate the inducing effects of stress on depression; instead, it inhibits this effect. Yet, the presence of compounds that affect dopaminergic, acetylcholine, glutamate, and opioid systems in the extract indicates that the extract induces different effects in different parts of the body, which results in reducing depression.

To recapitulate, with a $15 \%$ to $25 \%$ prevalence, depression is one the most common psychiatric disorders. It appears that the significant reducing effect of Papaver rhoeas L. hydroalcoholic extract on depression in mice can guide researchers in the quest for finding herbal antidepressants. It should be noted, however, that the present study investigated the shortterm administration of the hydroalcoholic extract of this plant, and it is recommended for future studies to examine the long-term use of this extract. Since this extract could effectively reduce depression, it is suggested that its constituent parts be isolated through phytochemical techniques and its effective components be used in the preparation of more effective antidepressants.

\section{Acknowledgements}

The present study was supported by a grant from Neurosciences Research Center of Baqiyatallah University of Medical Sciences.

\section{References}

Beck, T., A., Alford, B. A. (2009). Depression: Causes and treatment. Pensilvania, USA: University of Pennsylvania Press.

Berton, O., \& Nestler, E. J. (2006). New approaches to antidepressant drug discovery: Beyond monoamines. Nature Reviews Neuroscience, $7(2), 137-151$.

Blier, P., \& De Montigny, C. (1994). Current advances and trends in the treatment of depression. Trends in Pharmacological Sciences, 15(7), 220-226

Caspi, A., Sugden, K., Moffitt, T. E., Taylor, A., Craig, I. W., Harrington, $\mathrm{H}_{\text {., }}$ et al. (2003). Influence of life stress on depression: moderation by a polymorphism in the 5-HTT gene. Science, 301(5631), 386-389.

Dantzer, R., O'Connor, J. C., Freund, G. G., Johnson, R. W., \& Kelley, K. W. (2008). From inflammation to sickness and depression: when the immune system subjugates the brain. Nature Reviews Neuroscience, 9(1), 46-56.

Drevets, W. C., Price, J. L., \& Furey, M. L. (2008). Brain structural and functional abnormalities in mood disorders: Implications for neurocircuitry models of depression. Brain Structure and Function, 213(1-2), 93-118

Drew, A. K., \& Myers, S. P. (1997). Safety issues in herbal medicine: Implications for the health professions. Medical Journal of Australia, 166(10), 538-541.

Drugan, R. C., Morrow, A. L., Weizman, R., Weizman, A., Deutsch S. I., Crawley, J. N., et al. (1989). Stress-induced behavioral depression in the rat is associated with a decrease in GABA receptormediated chloride ion flux and brain benzodiazepine receptor occupancy. Brain Research, 487(1), 45-51.

El-Masry, S., El-Ghazooly, M. G., Omar, A. A., Khafagy, S. M., \& Phillipson, J. D. (1981). Alkaloids from Egyptian Papaver rhoeas. Planta Medica, 41(1), 61-64.

El, S. N., \& Karakaya, S. (2004). Radical scavenging and iron-chelating activities of some greens used as traditional dishes in Mediterranean diet. International Journal of Food Sciences and Nutrition, 55(1), 67-74.

Ettehadi, H., Mojabi, S. N., Ranjbaran, M., Shams, J., Sahraei, H., Hedayati, M., et al. (2013). Aqueous Extract of Saffron (Crocus sativus) Increases Brain Dopamine and Glutamate Concentrations in Rats. Journal of Behavioral and Brain Science, 3, 315-9.

Gürbüz, İ., Üstün, O., Yesilada, E., Sezik, E., \& Kutsal, O. (2003). Antiulcerogenic activity of some plants used as folk remedy in Turkey. Journal of Ethnopharmacology, 88(1), 93-97.

Hillenbrand, M., Zapp, J., \& Becker, H. (2004). Depsides from the petals of Papaver rhoeas. Planta Medica, 70(4), 380-382.

Kalav, Y. N., \& Sariyar, G. (1989). Alkaloids from Turkish Papaver rhoeas. Planta Medica, 55(5), 488

Krishnan, V., \& Nestler, E .J. (2011). Animal models of depression: Molecular perspectives. Current Topics in Behavior and Neuroscience, 7, 121-47.

Lucki, I. (1997). The forced swimming test as a model for core and component behavioral effects of antidepressant drugs. Behavioural Pharmacology, 8(6-7), 523. 
MacDonald, T. M. (1997). Treatment of depression: prescription for success? Primary Care in Psychiatry, 3, 7-10.

Mann, J. J. (2005). The medical management of depression. New England Journal of Medicine, 353(17), 1819-34.

Mirzaei, P., Lotfi Kashani, F., Behzadi, S., \& Sahraei, H. (2013). The effect of Papaver rhoeas distillate on learning, memory, corticosterone and anorexia in little laboratory mice under inescapable tension. Medical Science Journal of Islamic Azad Univesity, Tehran Medical Branch, 23(1), 21-29.

Nestler, E. J., Barrot, M., DiLeone, R. J., Eisch, A. J., Gold, S. J., \& Monteggia, L. M. (2002). Neurobiology of depression. Neuron, $34(1), 13-25$.

Pariante, C. M., \& Lightman, S. L. (2008). The HPA axis in major depression: classical theories and new developments. Trends in Neurosciences, 31(9), 464-468.

Pfeifer, S. (1965). On the occurrence of glaudine in opium and Papaver rhoeas L. Die Pharmazie, 20(4), 240-240.

Porsolt, R. D., Deniel, M., \& Jalfre, M. L. (1979). Forced swimming in rats: hypothermia, immobility and the effects of imipramine. European Journal of Pharmacology, 57(4), 431-436.

Porsolt, R. D., Le Pichon, M., \& Jalfre, M. L. (1977). Depression: A new animal model sensitive to antidepressant treatments. Nature, 266(5604), 730-732.

Pourmotabbed, A., Rostamian, B., Manouchehri, G., Pirzadeh-Jahromi, G., Sahraei, H., Ghoshooni, H., et al. (2004). Effects of Papaver rhoeas extract on the expression and development of morphinedependence in mice. Journal of Ethnopharmacology, 95(2), 431-435.

Raison, C. L., Capuron, L., \& Miller, A. H. (2006). Cytokines sing the blues: inflammation and the pathogenesis of depression. Trends in Immunology, 27(1), 24-31.

Sahraei, H., Shams, J., Faghih-Monzavi, Z., Zardooz, H., PashaeiRad, S., Pourmotabbed, A., et al. (2007). Effects of Papaver rhoeas. Extract on the Development and Expression of Tolerance to Morphine-Induced Locomotor Activity in Mice. Pharmaceutical Biology, 45(6), 475-480.

Sahraei, H., Faghih-Monzavi, Z., Fatemi, S. M., Pashaei-Rad, S., Salimi, S. H., \& Kamalinejad, M. (2006a). Effects of Papaver rhoeas extract on the acquisition and expression of morphine-induced behavioral sensitization in mice. Phytotherapy Research, 20(9), 737741

Sahraei, H., Fatemi, S. M., Pashaei-Rad, S., Faghih-Monzavi, Z., Salimi, S. H., \& Kamalinegad, M. (2006b). Effects of Papaver rhoeas extract on the acquisition and expression of morphine-induced conditioned place preference in mice. Journal of Ethnopharmacology, 103(3), 420-424.

Sarris, J. (2007). Herbal medicines in the treatment of psychiatric disorders: A systematic review. Phytotherapy Research, 21(8), 703-716.

Schaffer, S., Schmitt-Schillig, S., Muller, W. E., \& Eckert, G. P. (2005) Antioxidant properties of Mediterranean food plant extracts: Geographical differences. Journal of Physiology and Pharmacology, 56(1), $115-124$.

Saeed-Abadi, S., Ranjbaran, M., Jafari, F., Najafi-Abedi, A., Rahmani, B., Esfandiari, B., et al. (2012). Effects of Papaver rhoeas (L.) Extract on Formalin-induced Pain and Inflammation in Mice. Pakistan Journal of Biological Sciences, 15(21), 1041.
Shams, J., Sahraei, H., Faghih-Monzavi, Z., Salimi, S. H., Fatemi, S. M., Pourmatabbed, A., et al. (2010). Effects of Papaver rhoeas extract on the tolerance development to analgesic effects of morphine in mice. Iranian Journal of Pharmaceutical Research, 7, 141-7.

Soulimani, R., Younos, C., Jarmouni-Idrissi, S., Bousta, D., Khalouki, F., \& Laila, A. (2001). Behavioral and pharmaco-toxicological study of Papaver rhoeas L. in mice. Journal of Ethnopharmacology, 74(3), 265-274

Southwick, S. M., Vythilingam, M., \& Charney, D. S. (2005). The psychobiology of depression and resilience to stress: Implications for prevention and treatment. Annual Review of Clinical Psychology, 1, 255-91.

Winkler, W., \& Awe, W. (1961). On the structure of rhoeadine isomers isolated from Papaver rhoeas. Archiv der Pharmazie, 294, 301306

Zargari, A. (1994). Medicinal plants. Tehran, Iran: Tehran University Press. 
